\title{
ERICH FROMM: DA UTOPIA MESSIÂNICA À CRIMINOLOGIA CRITICA
}

ERICH FROMM: FROM MESSIANIC UTOPIA TO CRITICAL CRIMINOLOGY

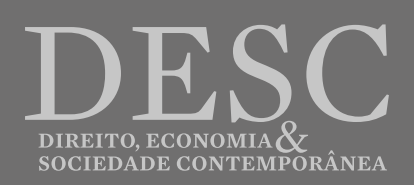




\title{
ERICH FROMM: DA UTOPIA MESSIÂNICA À CRIMINOLOGIA CRITICA ${ }^{1}$
}

\author{
ERICH FROMM: FROM MESSIANIC UTOPIA \\ TO CRITICAL CRIMINOLOGY
}

MICHAEL LÖWY

Michael.lowy1@gmail.com

Diretor emérito de pesquisas do Centre National de la Recherche Scientifique (CNRS - França)

\begin{abstract}
Resumo: Este capítulo explora os primeiros trabalhos de Erich Fromm nos anos 1920-1930, em particular, sua "afinidade eletiva" com o messianismo judaico, examinando as ligações entre o pensamento de Fromm, a tradição do marxismo messiânico e também os trabalhos de Freud, a partir do quais ele constrói as bases de desenvolvimento de uma criminologia crítica. Prossegue mostrando como o autor desenvolve uma profunda ligação entre justica punitiva (sistema penal) e sociedade de classes, transformando sua religiosidade numa dimensão utópica, que lhe permite conceber um outro modelo de sociedade oposta à sociedade capitalista.

Palavras-chave: Sistema de Justiça Penal. Justiça Punitiva. Criminologia crítica. Escola de Frankfurt. sociedade de classes. Ética econômica. Marxismo. Crítica Freudiana. Judaísmo.
\end{abstract}

\begin{abstract}
This chapter explores Erich Fromm's early works of the 1920-1930s, in particular, its 'elective affinity' with Jewish messianism, and examines the links between Fromm's work and the tradition of messianic Marxism and Freud's theory from which it draws its significance for the development of a critical criminology. It goes on to show how the author develops a deep connection between punitive justice and class society, transforming his religiosity into a utopian dimension that allows him to conceive another model of society opposed to capitalist society.
\end{abstract}

Keywords: Criminal Justice System. Criminal Justice. Critical Criminology. Frankfurt School. Class Society. Economic Ethic. Punitive Justice. Marxist criticism. Freudian criticism. Judaism.

1 Traduzido por 'Ariani Bueno Sudatti - Mestre e Doutora em Filosofia do Direito pela Faculdade de Direito da USP, Pós-Doutora em Literatura e História Literária pelo Departamento de Teoria Literária do IEL/ UNICAMP. 
Erich Fromm (1900-1980) é muito conhecido pelos seus ensaios na psicologia social, a maior parte deles escrito depois do seu exílio nos Estados Unidos, no final dos anos 30. Mas seus trabalhos anteriores - de 1922 a 1931 - são muito criativos, bem como politicamente radicais, merecendo ser discutidos. Eles têm alguns aspectos em comum: uma compreensão messiânica do Judaísmo, uma rejeição Freudiana-Marxista do capitalismo como sistema socioeconômico; uma crítica antiautoritária da justiça penal; e a aspiração por uma utopia socialista com raízes religiosas. Esses elementos reunidos estruturam um pensamento original e subversivo.

Depois de participar, com Martin Buber e Franz Rosenweig, da fundação da Casa Livre de Estudos Judaicos em Frankfurt, o jovem Fromm - naquele tempo um judeu convicto, apresenta em 1922, na Universidade de Heidelberg, sua tese de doutorado, orientada pelo sociólogo Alfred Weber, com o título A Lei Judaica. Contribuição para a sociologia da Diáspora Judaica; a qual seria publicada apenas setenta anos mais tarde, depois de sua morte. Pertencente à tradição da sociologia da cultura alemã, buscando entender a relação entre cultura religiosa e ética econômica, acaba tendo uma surpreendente tônica anticapitalista. Em uma das partes mais interessantes do livro, chamada "Labor e vocação (Beruf) no judaísmo rabínico"; diretamente inspirada por Max Weber, Fromm tenta demonstrar que, ao contrário da ética protestante, a judaica não é favorável ao espírito do capitalismo. A ética econômico-judaica seria, na terminologia de Weber, tradicionalista: o conhecimento e não o labor se coloca como o valor supremo; não por acaso, na narrativa bíblica da expulsão do paraíso, o trabalho é apresentado como uma maldição. Alternando citações bíblicas, talmúdicas e ... weberianas, Fromm argumenta: “em contradição direta com as concepções puritanas", a ética judaica não considera a aquisição de riqueza como um dever para com Deus; representando, portanto, "uma atitude não capitalista em relação à economia". Certamente, pode-se encontrar, nos tempos modernos, capitalistas judeus, mas, como Weber mostrou, trata-se de um "capitalismo pária", especulativo, político e aventureiro, em contraste com o etos puritano do empreendimento burguês racional, com sua organização racional do trabalho. ${ }^{2}$

O último capítulo do livro é dedicado ao Hassidismo, movimento popular místico, fundado na Polônia pelo rabino Isaac Ben Eliezer (1700-1760), o Baal Shem Tov (em hebraico 'Mestre do Bom Nome'), que Fromm define como um "Movimento social-religioso de auto-emancipação", radicalmente oposto ao espírito burguês capitalista. Por seu democratismo radical e seu misticismo comunitário, ele representa um "princípio social-religioso revolucionário". E por sua prática de fraternidade e ajuda mútua, ou ainda por sua mentalidade econômica tradicionalista (Gesinnung), o hassidismo desenvolve uma "atitude totalmente anticapitalista". ${ }^{3}$

Em 1924, Erich Fromm estabeleceu-se em Heidelberg, onde foi paciente da psicanalista

\footnotetext{
2 Erich Fromm, Das jüdische Gesetz. Zur Soziologie des Diaspora-Judentums, org. por Ranier Funk e Bernd Sahrler, Basel, Beltz 1989, pp. 41-54.

3 Ibid. pp. 161-184
} 
freudiana-ortodoxa Frieda Reichmann, com quem se casou em 1926. Provavelmente, foi o impacto de sua análise que o fez perder sua fé religiosa - mesmo que seu pensamento permanecesse sempre profundamente tingido de religiosidade. Em 1927, publicou seu primeiro trabalho psicanalítico, na Revista Imago, editada por Sigmund Freud. O artigo, Der Shabbath, é uma peça bastante surpreendente com um poderoso ímpeto messiânico, apesar da linguagem científica. Segundo Fromm, a interdição do trabalho durante o sábado judaico significa uma suspensão da violação da Mãe Terra pelo homem. Proibindo estrita e severamente qualquer forma de trabalho durante o sábado, a religião judaica buscava o restabelecimento (Wiederherstellung) do estado paradisíaco sem trabalho, a harmonia entre o homem e a natureza. De acordo com Fromm:

\begin{abstract}
"Os profetas consideravam o tempo messiânico como uma condição na qual a luta entre o homem e a natureza chegaria ao fim (...) Se o homem fosse expulso do Paraíso porque quisera ser como Deus - isto é, igual ao pai, capaz de conquistar a mãe - e se o trabalho era punição para essa brecha primal (Urverbrechen), então, segundo os profetas, no período messiânico, os seres humanos viveriam mais uma vez em completa harmonia com a natureza, ou seja, sem ter que trabalhar, no Paraíso, o equivalente ao ventre da mãe ". 4
\end{abstract}

Mais uma vez, a religião judaica está se opondo à ética protestante do trabalho, como em sua tese de doutorado, mas desta vez com um argumento freudiano específico e um horizonte messiânico-utópico.

Em 1930, Fromm foi nomeado por Max Horkheimer - o chefe do Instituto de Pesquisa Social (a Escola de Frankfurt) - diretor da Seção de Psicologia Social da I.P.S A tentativa de Fromm de combinar o marxismo e o freudismo está no cerne de suas obras nos anos seguintes. Seu primeiro trabalho importante neste campo - publicado pela primeira vez como um grande ensaio na revista Imago de Freud - foi o livro O dogma de Cristo (1931): esse novo interesse pelos evangelhos não está em desacordo com suas preocupações judaicas anteriores, já que ele considera o cristianismo como um sucessor direto do messianismo judaico, lutando contra o império romano.

Na opinião de Fromm, o cristianismo era originalmente "um movimento revolucionário messiânico", trazendo a mensagem da expectativa escatológica, a iminência do Reino de Deus. A comunidade cristã primitiva era "uma irmandade de pessoas pobres e livre", intensamente hostil a toda autoridade ou poder "paterno". O mito cristão original mostrava Cristo como o Messias sofredor que foi elevado à dignidade de Deus; isso trazia uma hostilidade oculta a Deus, o Pai, o Imperador e a autoridade em geral. O cristianismo era a expressão das tendências revolucionárias, das expectativas e anseios das massas oprimidas - primeiro judeus e depois gentios - que se agrupavam em uma "organização comunitária sem autoridades, status ou burocracia". 5

Contudo, a partir do terceiro século, os fundamentos sociais do cristianismo foram

\footnotetext{
4 E.Fromm, "Der Sabbath”, Imago, vol. XIII, Vienna, Internationaler Psychoanalytsicher Verlag, 1927, pp. 226, 228, 233.

5 E.Fromm, The Dogma of Christ and Other Essays on Religion, Psychology and Culture, New York, Holt, Rhinehart and Winston, 1963, pp. 35-49.
} 
transformados, quando se tornou a religião das classes superiores do Império Romano. As crenças sobre Cristo foram então profundamente modificadas: o homem elevado à dignidade de Deus tornou-se o Filho do Homem, que sempre foi Deus (dogma da consubstanciação). Ao mesmo tempo, a esperança escatológica de libertação histórica real foi gradualmente substituída pela ideia de que a salvação seria uma libertação interna, espiritual, não histórica e individual. Finalmente, em íntima associação com essa negação do messianismo, houve uma crescente reconciliação entre Igreja e Estado. Em outras palavras, "o cristianismo, que era a religião de uma comunidade de irmãos iguais, sem hierarquia ou burocracia, tornou-se "a Igreja", a imagem refletida da monarquia absoluta do Império Romano". Juntamente com essa transformação de uma confraria livre em uma organização autoritária e hierárquica, houve também uma mudança psíquica: aquela hostilidade em relação ao pai, o desprezo cristão primitivo pelos ricos e poderosos, por toda autoridade, foi sendo substituído por reverência e subordinação às novas autoridades administrativas. Impulsos agressivos, originalmente dirigidos contra o pai, voltaram-se contra o eu de uma maneira que não representava perigo para a estabilidade social; induzindo assim, um sentimento geral de culpa - junto com uma necessidade masoquista de expiação. ${ }^{6}$

O Dogma de Cristo foi saudado por Franz Borkenau no Zeitschrift für Sozialforschung - a Revista do Instituto de Pesquisa Social - como o primeiro exemplo concreto de uma síntese entre Freud e Marx. ${ }^{7}$ Apesar de não pertencer ao grupo central, Fromm foi associado à Escola de Frankfurt durante a década de 1930 e publicou vários ensaios e artigos em sua revista, que foi editada por Max Horkheimer.

O que chama a atenção em sua interpretação do marxismo e do freudismo é sua forte orientação antiautoritária. Encontramos a mesma tendência em seus ensaios de criminologia, publicados na mesma época, 1930-1931. Em grande parte esquecidos durante décadas ${ }^{8}$, estes ensaios foram recentemente traduzidos para o inglês e editados, por Kevin Anderson e Richard Quinney, com vários outros ensaios sobre Fromm. Em seu prefácio, os dois editores enfatizam a importância da crítica humanista de Fromm à justiça penal visando uma criminologia crítica e sua relevância em uma sociedade americana que parece inclinada, em grau sem precedentes, à prisão em massa e a execuções, como resposta ao problema do crime. ${ }^{9}$

O primeiro desses artigos, "O Estado como Educador: Sobre a Psicologia da Justiça Criminal” (Der Staat als Erzieher: Zur Psychologie der Strafjustiz), apareceu na revista sobre

\footnotetext{
6 Ibid. pp. 56-65.

7 Apud Martin Jay, The Dialectical Imagination. A History of the Frankfurt School and the Institute of Social Research, Boston, Little Brown and Company, 1973, p.91.

8 Eu discuto brevemente esses artigos no meu livro Redemption and Utopia. Libertarian Judä̈sm in Central Europe. A Study in Elective Affinities, Stanford, Stanford University Press, 1980, pp. 153-154.

9 Erich Fromm and Critical Criminology. Beyond the Punitive Society, Edited by Kevin Anderson and Richard Quinney, traduzido para o alemão e anotado por Heinz D.Osterle and Kevin Anderson, Urbana, University of Illinois Press, 2000 , p. vii.
} 
psicanálise educacional, Zeitschrift für psychoanalythisce Pädaogogik, ${ }^{\circ}{ }^{4}$.1, janeiro de 1930 . Entre os editores da revista estão: Siegfried Bernfeld - um marxista-freudiano que foi uma referência importante para Erich Fromm - Sandor Ferenczi, Anna Freud e outros. O objetivo do ensaio é lidar com as características problemáticas de instituições autoritárias, como o sistema judicial. ${ }^{10} \mathrm{O}$ ponto de partida de Fromm são os primeiros trabalhos psicanalíticos sobre criminologia de Fritz Wittels, Franz Alexander e Hugo Staub - todos publicados em 1928 - que documentam o quase total fracasso dos objetivos oficiais declarados pela justiça punitiva (Strafjustiz): a recuperação ou correção do criminoso, ou a dissuasão do crime. Agora, se o sistema de justiça criminal é tão ineficaz na consecução de seus próprios objetivos, quais são as razões pelas quais as forças dominantes da sociedade mantêm tais medidas com tanta determinação? ${ }^{11}$

A resposta de Fromm é uma poderosa e original acusação marxista-freudiana da justiça punitiva (Strafjustiz) como um meio de dominação de classe:

"De maneira alguma a estabilidade da estrutura social depende unicamente da força dos instrumentos externos de poder (...). Com certeza, a polícia e os militares são fortes apoios para a sociedade, mas eles podem - como mostra a história das revoluções - apenas cumprir suas obrigações quando um fator adicional entra em jogo. Este fator adicional é a prontidão psíquica da grande maioria para se ajustar (sich einzufügen) à sociedade existente e subordinar-se (sich unterzuordnen) aos poderes dominantes. "Há, é claro, uma grande diversidade de tais" fatores psíquicos "- e Fromm se refere ao ensaio de Siegfried Bernfeld, de 1928, sobre o lugar da escola na luta de classes -, mas um dos mais importantes fatores é justamente a justiça punitiva:

"A sociedade contemporânea, como todas as anteriores, baseia-se na severa renúncia instintiva (Triebverzicht) por parte das massas, na subordinação das massas às camadas dominantes e, do lado psicológico, na crença de que as relações sociais existentes são necessárias (Notwendig); especificamente, que elas estão fundadas num insight de superioridade e sabedoria dos governantes. Essas atitudes psíquicas têm seu modelo e sua origem na atitude da criança para com o pai. (...) A atitude psíquica (seelische Einstellung) da criança em relação ao pai é a mesma que os Estados desejam e consideram necessária para a grande massa de seus cidadãos. O Estado deve usar todos os meios possíveis para se apresentar às massas como imagem paterna (Vaterimago), e desta forma, tornar possível ao indivíduo transferir sua atitude anterior em relação ao pai para os governantes" ${ }^{\prime 2}$.

Em outras palavras: o objetivo principal da justiça punitiva não é "reeducar" os criminosos, mas “educar" as pessoas:

"Resta claro, portanto, porque deve haver um sistema de justiça punitiva, independente de seu efeito (Einwirkung) sobre os criminosos. É uma instituição através da qual o Estado impõe sua vontade como imagem paterna no inconsciente das massas, na qual se repete uma importante função do pai, seu poder de punir e ameaçar. Isto é mais claramente visível na pena de morte." 13

10 ibid. p. 124. O tradutor verteu a expressão autoritätsgetragen para "venerable established institutions"; Eu prefiro "authoritarian institutions" (instituições autoritárias).

11 Nota do autor: O tradutor do texto alemão para o inglês usou "criminal justice", "justiça criminal" para o termo alemão Strafjustiz; Preferi "justiça punitiva"...

12 E.Fromm, "The State as Educator; On the Psycology of Criminal Justice", in Erich Fromm and Critical Criminology, pp. 124-125. O tradutor adotou a expressão "criminal justice" para se referir à Strafjustiz. Eu prefiro uma tradução mais literal e por isso adoto "justiça punitiva".

13 Ibid. p. 126. 
Fromm não menciona o fascismo - em 1930, pois o perigo do nazismo não parecia iminente -, mas sua análise é bastante relevante para compreender as raízes psicológicas dos desenvolvimentos que ocorreram depois de 1933, sob a ditadura do Führer Adolf Hitler. A conclusão do ensaio é um apelo mal disfarçado para um revolucionário radical? - A transformação da sociedade:

\begin{abstract}
"O resultado dessas considerações é que todo o insight sobre a ineficácia do sistema de justiça punitiva contemporâneo em relação ao criminoso dificilmente levará a mudanças básicas no sistema, contanto que a estrutura peculiar (Eigenart) da sociedade atual prevaleça. A sociedade precisa do sistema de justiça punitiva para fins que nada têm a ver com abordagens eficazes (zeckmässiges Verhalten) em relação ao criminoso. O sistema de justiça criminal é um instrumento para "educar" (Erziehung) as massas, no sentido de fixá-las artificialmente à situação em que uma pessoa é "educada" (erzogen). É a situação da criança que reverencia o pai ". ${ }^{14}$
\end{abstract}

A crítica antiautoritária, quase anarquista, do poder do Estado, do domínio de classe e da dominação do Pai - comum a este ensaio e ao livro sobre o cristianismo - é um dos traços distintivos dos primeiros escritos freudiano-marxistas de Fromm.

O segundo artigo de Fromm em "criminologia crítica", "Sobre a psicologia do criminoso e da sociedade punitiva" (Zur Psychologie des Verbrechers und der Strafenden Gesellschaft), foi publicado no ano seguinte (1931) na revista oficial freudiana Imago. É menos radical que o primeiro, mas em grande parte segue uma orientação similar. A primeira parte, a menos interessante, trata da psicologia neurótica do criminoso e da respectiva importância dos motivos econômicos e instintivos do crime. Fromm também discute os estudos dos criminologistas liberais, Franz von Liszt e Gustav Aschaffenburg, que documentam o fracasso da punição legal para alcançar seus objetivos oficiais: recuperação do criminoso, dissuasão do crime e proteção da sociedade. Se esse é o caso, por que a sociedade mantém medidas cuja ineficácia com relação aos propósitos pretendidos foi claramente demonstrada? "Aparentemente, o sistema de justiça punitiva também tem outra, como se fosse uma função oculta, que funciona satisfatoriamente e com precisão. É por causa dessa função oculta que o sistema não está sendo abandonado, embora seja manifestamente incapaz de cumprir seus objetivos oficialmente declarados". ${ }^{15}$

O que seria essa "função oculta"? Tentando responder a tal pergunta, na última parte do ensaio, Fromm assume uma posição semelhante a de seu artigo anterior, denunciando, em uma composição ímpar de instrumentos analíticos de referências marxistas e freudianas, a verdadeira missão da justiça punitiva. Seu primeiro passo é deixar claro que a dominação não pode existir sem alguns requisitos psíquicos:

“Toda sociedade de classes é caracterizada pela dominação de uma classe sobre outra, mais especificamente, pelo pequeno estrato da propriedade sobre a grande massa daqueles destituídos de propriedade. Os meios pelos quais essa dominação é exercida são bastante

14 Ibid. pp. 126-127.

15 E.Fromm, "On the Psychology of the Criminal...." in Erich Fromm and Critical Criminology, cit. p 144. 
variados ". Eles incluem, é claro, a violência, porém mais importantes ainda são os meios psicológicos, que tornam necessária a violência explícita apenas em casos excepcionais.

"Esse meio psicológico consiste no fato de que as massas são colocadas em uma situação de apego psíquico e dependência da classe dominante ou de seus representantes para que eles a obedeçam e se subordinem a ela sem que seja necessário apelar ao uso da violência”. ${ }^{16}$

$\mathrm{O}$ argumento de Fromm parece ser uma tentativa de dar um fundamento freudiano ao conceito de "servidão voluntária", elaborado no século XVI por Etienne de la Boétie, o qual foi traduzido para o alemão no início do século XX pelo anarquista judeu-alemão Gustav Landauer, cujos escritos eram familiares a Fromm.

Qual é o significado da justiça punitiva nesta configuração psíquica? De acordo com Fromm:

\begin{abstract}
"É um dos requisitos mais importantes para a estabilidade social da sociedade de classes que as massas transfiram essa atitude infantil da criança para com o pai em relação à classe dominante e seus representantes. (...) Os meios pelos quais a classe dominante se impõe sobre as massas como figura paterna são bastante variados. Um deles, e não o menos importante, é a justiça punitiva. Demonstra um dos atributos mais essenciais do pai, seu poder de punir, e gera o medo que torna uma atitude de reverência amorosa preferível à rebelião. (...) Portanto, o Estado, como representante da classe dominante, deve atribuir a si mesmo esse poder de punir ". ${ }^{17}$
\end{abstract}

Para concluir: “A justiça punitiva é um requisito psicológico indispensável para uma sociedade de classes". ${ }^{18}$ Segundo Erich Fromm, a crítica radical de Strafjustiz é inseparável de um enfrentamento radical da dominação de classe, do Estado e da autoridade paterna e, portanto, está implícita numa utopia emancipatória. Como Kevin Anderson muito perspicazmente comenta, "as formulações de Fromm, enraizadas numa perspectiva dialética e humanista, apontam para além do estado de coisas existente em direção a uma sociedade humanista mais pacífica, livre de repressão (...) na qual os seres humanos pudessem exercer livremente suas capacidades criativas. Foi a partir desse ponto de vista que ele estruturou uma crítica radical do sistema de justiça punitiva na perspectiva de uma sociedade de classes ". ${ }^{19}$ Essa utopia de uma sociedade liberta e pacífica, sem Strafjustiz, é uma versão secularizada e profana da utopia messiânica de seus primeiros escritos.

\footnotetext{
16 Ibid. p.145.

17 Ibid. p. 145-146.

18 Ibid. p. 147.

19 Kevin Anderson, "Erich Fromm and the Frankfurt School Critique of Criminal Justice", em Erich Fromm and Critical Criminology, p. 113.
} 


\section{Referências bibliográficas:}

ANDERSON, K. and QUINNEY, R. (eds). Erich Fromm and Critical Criminology: Beyond the Punitive Society. Urbana: University of Illinois Press. (2000)

ANDERSON, K. 'Erich Fromm and the Frankfurt School Critique of Criminal Justice', in Anderson, K. and R. Quinney (eds). Erich Fromm and Critical Criminology: Beyond the Punitive Society. Urbana: University of Illinois Press. (2000)

FROMM, Erich. 'Der Sabbath', Imago. Vienna: Internationaler Psychoanalyt sicher Verlag, XIII: 226233. (1927)

Der Staat als Erziehher: Zur Psychologie der Strafjustiz. Zeithschrift fur psychoanalythisce Padagogik, 4:1. 1930.

. 'The State as Educator: On the Psychology of Criminal Justice', in K. Anderson and R. Quinney (eds). Erich Fromm and Critical Criminology: Beyond the Punitive Society. Urbana: University of Illinois Press. 1930.

. 'On the Psychology of the Criminal and the punitive society', in K. Anderson and R. Quinney (eds). Erich Fromm and Critical Criminology: Beyond the Punitive Society. Urbana: University of Illinois Press. 1931.

The Dogma of Christ and Other Essays on Religion, Psychology and Culture.

New York: Hold, Rhinehart and Winston. 1963.

Das judische Gesetz: Zur Soziologie des Diaspora Judentums. Basel, Beltz: Ranier Funk and Bernd Sahrler. 1989.

JAY, M. The Dialectical Imagination: A History of the Frankfurt School and the Institute of Social Research. Boston: Little Brown and Company. 1973.

LÖWY, Michael. Redemption and Utopia: Libertaria Judaism in Central Europe: A Study in Elective Affinities. Stanford: Stanford University Press. 1980.

\section{SOBRE O AUTOR:}

Michael Löwy

Sociólogo nascido no Brasil, formado em Ciências Sociais na Universidade de São Paulo, foi professor da École des Hautes Études en Sciences Sociales (EHESS, França) e Diretor emérito de pesquisas do Centre National de la Recherche Scientifique (CNRS - França). 